\title{
Crystallization in the waterjet channel in colono- scopes due to simethicone
}

$$
\left.\left(\mathrm{H}_{3} \mathrm{C}\right)_{3} \mathrm{Si}-\mathrm{O}-\mathrm{Si}\left(\mathrm{H}_{3} \mathrm{C}\right)_{2}-\mathrm{O}\right]_{\mathrm{n}} \mathrm{Si}\left(\mathrm{H}_{3} \mathrm{C}\right)_{3}
$$

Fig. 1 Chemical structure of simethicone, as used in Lefax.

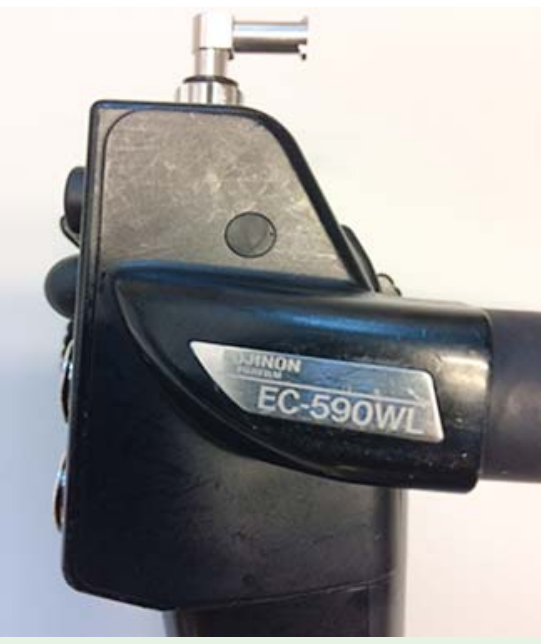

Fig. 2 The colonoscope waterjet connector where crystal deposits were observed.

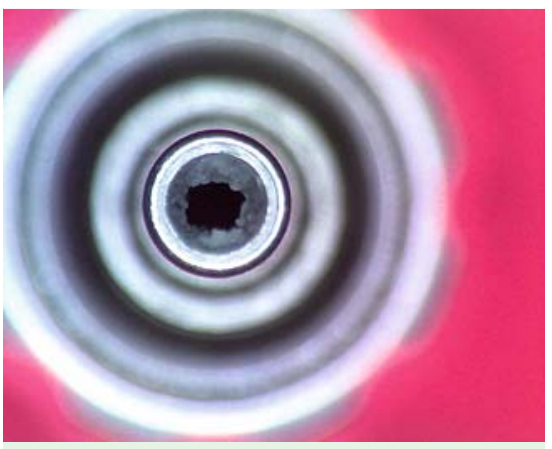

Fig. 3 Crystal deposits within the connector.

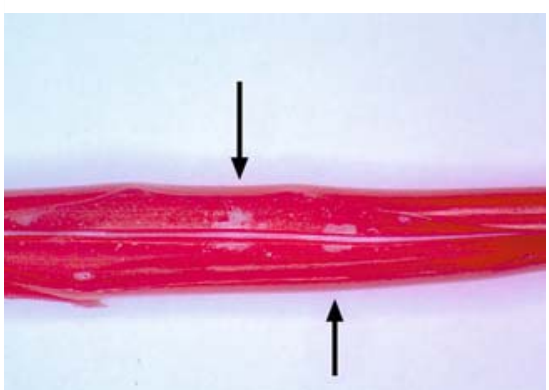

Fig.4 Crystal deposits within the waterjet channel (tube cut open) (arrows).
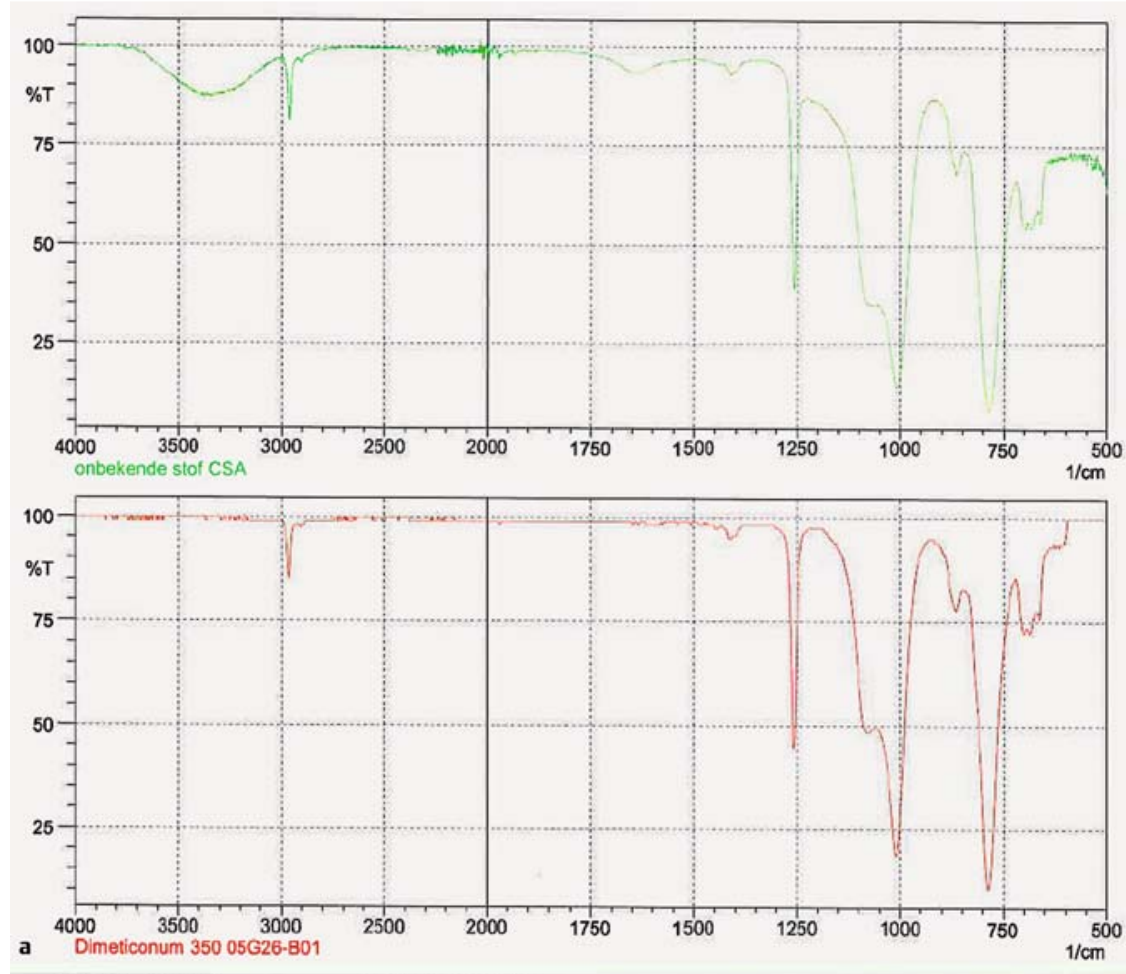

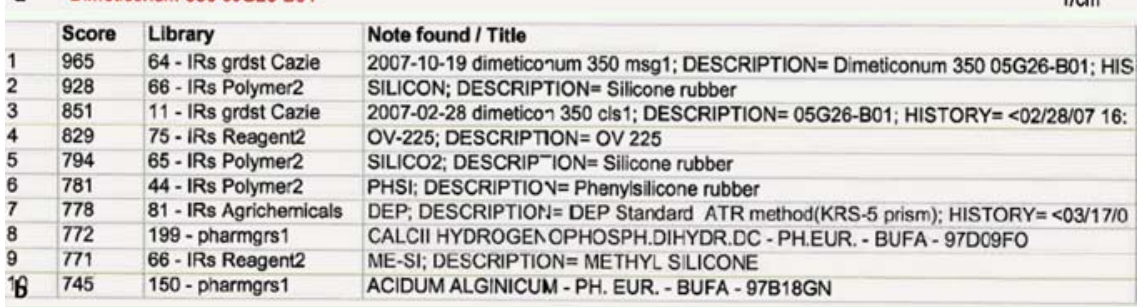

Fig. 5 a, b Result of the infrared spectral analysis, showing the presence of dimethicone.

Colonoscopy is the preferred diagnostic and therapeutic modality in the lower intestinal tract. Most Dutch hospitals use Lefax (Bayer Vital GmbH, Leverkusen, Germany) to optimize endoscopic imaging. The main component of Lefax is simethicone $(\bullet$ Fig. 1$)$, a silicon dioxide crystalloid of the silicone polymer dimethicone, which decreases the surface tension of bubbles. Lefax is added to water and injected via the waterjet channel of the colonoscope to create a powerful and directional beam.

Recently, a waterjet channel connector (৫ Fig. 2) broke off a colonoscope (Fujinon EC-590 WL; Fujifilm Corporation, Tokyo, Japan) in our department. During repair, crystalline deposits were noticed inside the connector ( $\bullet$ Fig.3). Closer examination revealed deposits in every compo- nent within the channel ( $\bullet$ Fig.4). Infrared spectral analysis by our clinical pharmacy laboratory showed that the crystals consisted of dimethicone ( $\bullet$ Fig. $\mathbf{5}$ a, b).

A total of 16 colonoscopies are used in our department. All of them are Fujinon scopes, from the series EC-530 WI-H $(\mathrm{n}=$ 1), EC-590 WL $(n=3), E C-590$ WL4 $(n=3)$, and EC-600 WL ( $n=9)$, and all had crystal deposits.

Crystals could only be seen by thorough inspection, not during regular checkups. Elimination of the crystals was only possible by mechanical cleaning after the connector had been removed and the channel opened. Repeated attempts at washing with (warm) water, peracetic acid, and precleaning detergent (Neodisher SC; Dr Weigert, Mühlenhagen, Hamburg, Germany) were unsuccessful. As the connec- 
tor has a $90^{\circ}$ angle and the waterjet channel is only $1.2 \mathrm{~mm}$ in diameter, this channel can only be cleaned by flushing, not by mechanical means. Crystal deposits may therefore eventually lead to occlusion of the waterjet channel. When deposits remain, flushing may no longer be effective for cleaning, increasing the risk of microbiological film formation and patient contamination. No such cases have yet been seen in our department.

The presence of dimethicone crystal deposits in colonoscope waterjet channels has potentially important clinical consequences. Simethicone is used in many endoscopy departments, both within and outside the Netherlands, and no alternative product with the same properties is available. It must be stressed that the use of Lefax in colonoscope waterjet channels is off-label; according to the manufacturer only water should be used.

Following this discovery Lefax has only been used via the colonoscope working channel in our department, leading to less than optimal focal cleansing. It is important that endoscopy units outside the Netherlands are informed about these findings, which have not been reported previously.

Endoscopy_UCTN_Code_CPL_1AN_2AF

Competing interests: None

Stephan H. C. van Stiphout ${ }^{1}$, Ilse F. M. Laros ${ }^{2}$, Ralph A. C. van Wezel ${ }^{3}$, Lennard P. L. Gilissen ${ }^{1}$

${ }^{1}$ Department of Gastroenterology and Hepatology, Catharina Hospital Eindhoven, Eindhoven, Netherlands

2 Department of Hospital Hygiene and Infection Prevention, Catharina Hospital Eindhoven, Eindhoven, Netherlands

${ }^{3}$ Department of Clinical Pharmacy, Catharina Hospital Eindhoven, Eindhoven, Netherlands

\section{Acknowledgment}

$\nabla$

Photographs courtesy of R. Karsemakers, Technical Department, Endoscopy, Catharina Hospital Eindhoven, Netherlands.

Bibliography

DOI http://dx.doi.org/ 10.1055/s-0042-120261

Endoscopy 2016; 48: E394-E395

(C) Georg Thieme Verlag KG

Stuttgart · New York

ISSN 0013-726X

\section{Corresponding author}

Stephan H. C. van Stiphout, MD

Catharina Hospital Eindhoven

Michelangelolaan 2

PO Box 1350

5602 ZA Eindhoven

Netherlands

Fax: +31-40-2399751

shcvanstiphout@gmail.com 